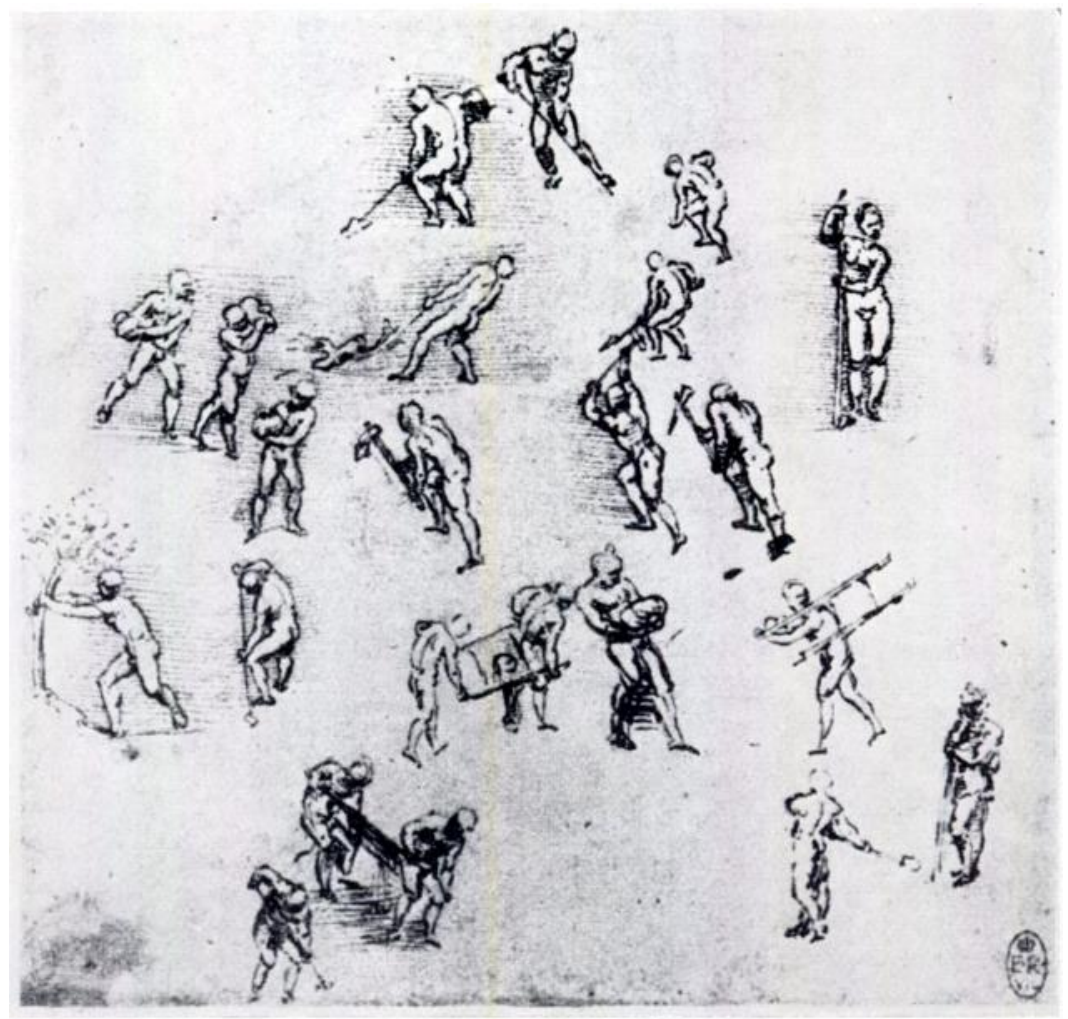

FIG. 6

Figures of labourers, including a man with a ladder on his shoulder. Drawings by Leonardo da Vinci in the Royal Collection (Clark, MacCurdy). By gracious permission of H.M. The Queen.

collection till it was discovered at that Palace in 1760 , seventeen years after the English publication of Andry's book.

More than two centuries after Leonardo's death, his physiological observations on posture and balance were adapted and expanded by Andry in the treatment of postural defects by active correction. Two centuries later still his lessons are not yet fully learnt.

H. JACKSON BURrows.

\title{
REFERENCES
}

ANDry, N. (1743): Orthopaedia: Or, the Art of Correcting and Preventing Deformities in Children: By such Means, as may easily be put in Practice by Parents themselves, and all such as are employed in Educating Children. Two volumes. London: Printed for A. Millar, at Buchanan's Head, opposite to Catherine-street, in the Strand.

CLARK, K. (1935): A Catalogue of the Drawings of Leonardo da Vinci in the Collection of His Majesty the King at Windsor Castle. Cambridge University Press.

MacCUrdy, E. (1938): The Notebooks of Leonardo da Vinci. London: Jonathan Cape.

Richter, J. P. (1883): The Literary Works of Leonardo da Vinci compiled and edited from the Original Manuscripts. Two volumes. London: Sampson Low, Marston, Searle and Rivington.

\section{RESEARCH FELLOWSHIP IN ORTHOPAEDIC SURGERY}

Attention is drawn to the Research Fellowship in Orthopaedic Surgery with a renumeration of $£ 4,500$ which is now offered by the Royal College of Surgeons of England in memory of Laming Evans. Details are noted in later pages of the Journal. 